\title{
Effect of invader removal: pollinators stay but some native plants miss their new friend
}

\author{
Victoria Ferrero $\cdot$ Sílvia Castro $\cdot$ Joana Costa \\ Paola Acuña $\cdot$ Luis Navarro $\cdot$ João Loureiro
}

Received: 24 September 2012/Accepted: 5 April 2013/Published online: 17 April 2013

(C) Springer Science+Business Media Dordrecht 2013

\begin{abstract}
Removal of invasive species often benefits biological diversity allowing ecosystems' recovery. However, it is important to assess the functional roles that invaders may have established in their new areas to avoid unexpected results from species elimination. Invasive animal-pollinated plants may affect the plant-pollination interactions by changing pollinator availability and/or behaviour in the community. Thus, removal of an invasive plant may have important effects on pollinator community that may then be reflected positive or negatively on the reproductive success of native plants. The objective of this study was to assess the effect of removing Oxalis pescaprae, an invasive weed widely spread in the Mediterranean basin, on plant-pollinator interactions and on the reproductive success of co-flowering native plants. For this, a disturbed area in central Portugal, where this species is highly abundant, was selected.
\end{abstract}

Electronic supplementary material The online version of this article (doi:10.1007/s10530-013-0457-4) contains supplementary material, which is available to authorized users.

V. Ferrero $\cdot$ S. Castro $\cdot$ J. Costa $\cdot$ J. Loureiro

CFE, Centre for Functional Ecology and Department of Life Sciences, University of Coimbra, PO Box 3046, 3001-401 Coimbra, Portugal

V. Ferrero $(\varangle) \cdot$ P. Acuña $\cdot$ L. Navarro Department of Plant Biology, Faculty of Science, University of Vigo, As Lagoas-Marcosende, 36200 Vigo, Spain

e-mail: victoferrero@uvigo.es
Visitation rates, natural pollen loads, pollen tube growth and natural fruit set of native plants were compared in the presence of $O$. pes-caprae and after manual removal of their flowers. Our results showed a highly resilient pollination network but also revealed some facilitative effects of $O$. pes-caprae on the reproductive success of co-flowering native plants. Reproductive success of the native plants seems to depend not only on the number and diversity of floral visitors, but also on their efficiency as pollinators. The information provided on the effects of invasive species on the sexual reproductive success of natives is essential for adequate management of invaded areas.

Keywords Biological invasions - Competition . Facilitation · Mutualistic relationships - Oxalis pescaprae $\cdot$ Plant-pollinator networks

\section{Introduction}

It is currently known that biological invasions can alter the community composition and structure of invaded areas (Vitousek 1990; Traveset and Richardson 2006; Vilà et al. 2009), being the removal of invasive species a method frequently used to restore ecosystems (Veitch and Clout 2002). The impacts of invasive plant species on diversity and composition of native plants in invaded communities, through competition for abiotic resources, such as space, soil nutrients, light and water, have been largely considered (Levine et al. 
2003); however, invasive plants can also act as potential disrupting agents of native mutualistic interactions (Richardson et al. 2000; Traveset and Richardson 2006; Montero-Castaño and Vilà 2012). In particular, invasive animal-pollinated plants may affect the native plant-pollinator interactions (Richardson et al. 2000; Mitchell et al. 2006; Traveset and Richardson 2006) by altering pollinator availability and/or behaviour (reviewed in Bjerknes et al. 2007; e.g. Brown et al. 2002; Bartomeus, et al. 2008a, b; Muñoz and Cavieres 2008). Thus, invasive plants can act as competitors, if they attract preferentially more pollinators, reducing the visitation rates to native plants (e.g. Grabas and Laverty 1999; Chittka and Schürkens 2001; Totland et al. 2006), or they can facilitate the pollination of the native plants by increasing the pollination services available in the community (Bjerknes et al. 2007; McKinney and Goodell 2011). Such effects may have negative, positive, or neutral consequences on the reproductive success of the native plants through alterations on the conspecific/heterospecific pollen loads on the stigmas depending on their levels of pollen limitation (e.g. Moragues and Traveset 2005; Larson et al. 2006; Bartomeus et al. 2008a).

Successful removal of invasive species often benefits biological diversity by leading to the recovery of native species and ecosystems. However, there are examples where the removal of an invasive species has brought unexpected impacts (Zavaleta et al. 2001; Veitch and Clout 2002). In order to minimize negative effects of invasive species' removal, it is desirable to quantitatively evaluate the interactions between invasive and native species and the potential functional roles played by invasive species in the new areas (Zavaleta et al. 2001). Network analysis has already been used to predict the impact of removing invasive species on pollination services at the community level (e.g. Memmott et al. 2004; Valdovinos et al. 2009). However, there are just a few studies that tested empirically how an invasive plant species may affect plant-pollinator interactions (e.g. Lopezaraiza-Mikel et al. 2007; Bartomeus et al. 2008b; Carvalheiro et al. 2008; King and Sargent 2012), and only a few studies considered the actual impact that invasive species may have on the sexual reproductive success of coflowering natives (e.g. Morales and Traveset 2009).

In the Mediterranean basin, Oxalis pes-caprae L. (Oxalidaceae) was introduced at the end of the nineteenth century as an ornamental plant, being currently widespread in Greece, Italy, North Africa and in the Iberian Peninsula (Damanakis and Markaki 1990; Brandes 1991). Its capacity to produce bulbs together with the contractile properties of its roots strongly favoured clonality and rapid spread (Galil 1968; Pütz 1994), promptly becoming a noxious weed difficult to eradicate. Like many invasive species, $O$. pes-caprae is extremely common in habitats disturbed by anthropogenic activities, such as, crop areas and road sides (Gimeno et al. 2006).

The objective of this study was to assess whether the removal of $O$. pes-caprae flowers altered the number of plant-pollinator interactions and the sexual reproductive success of co-flowering native plants which present different breeding systems. In particular, our questions were the following: (1) Does the presence of $O$. pes-caprae floral resources modify the native plant-pollinator interactions? For this, the visitation rates to native plants and the plant-pollinator interactions were evaluated in the presence of $O$. pes-caprae flowers and after their removal; in addition, the impact of $O$. pes-caprae on native pollinator communities was studied using a network analytical approach. (2) Is $O$. pes-caprae affecting the reproductive success of co-occurring natives? To address this question, natural pollen loads, pollen tubes and natural fruit set of native plants were also compared in the presence of $O$. pes-caprae floral resources and after their removal.

\section{Materials and methods}

Study site and plant species

This experiment was carried out in a rural area in central Portugal, namely Castelo Viegas, Coimbra, Portugal $\left(40^{\circ} 09^{\prime} 55.9^{\prime \prime} \mathrm{N} ; 8^{\circ} 24^{\prime} 26.9^{\prime \prime} \mathrm{W}\right)$ at the end of March 2011. The community consisted in a patch of about $500 \mathrm{~m}^{2}$ containing six native species synchronously flowering with Oxalis pes-caprae L. Voucher specimens from the Herbarium of the University of Coimbra (COI) were used to assess the phenology of the flowering species in the area studied. The phenology of the native species was additionally confirmed with data available at Castroviejo et al. (1986-2012) for the Iberian Peninsula. The native species comprised four self-compatible and two self-incompatible 
species. Phenological and reproductive features of the native species studied are summarized in Table 1 . The total abundance of native flowers was calculated by multiplying the average number of flowers counted in the selected monitored plots (see above) by the rest of the area they occupied. O. pes-caprae was highly abundant in the community (approximately 10,000 flowers). Additional information on the biology of $O$. pes-caprae in this invasive range can be found in Castro et al. (2007, 2013) and Costa et al. (2013).

\section{Visitation rates}

Six square plots of approximately $12 \mathrm{~m}^{2}$ were selected to incorporate all the species present in the community and were characterized for the number of open flowers per plant species. In each plot, flower visitation censuses were carried out to characterize the floral visitors during 4-5 consecutive days at different periods of the day from 9:00 $\mathrm{h}$ to 18:00 $\mathrm{h}$. After this, all the $O$. pes-caprae flowers present in the community were removed by cutting the inflorescences without damaging or disturbing the soil properties; finally, censuses were repeated in the same plots with the same effort allocation. Both treatments were carried out in a short period of time ( $<2$ weeks). During this period, the climatic conditions were fairly homogenous. In the closest meteorological station, Airport of Coimbra/ Cernache, the mean temperature registered during observations was $15.9^{\circ} \mathrm{C}$ and the mean relative humidity was $60.9 \%$ along the 2 weeks. A total of 277 censuses of 15 min were carried out, corresponding to $31 \mathrm{~h}$ of observation in the presence of $O$. pescaprae flowers and $38 \mathrm{~h}$ after their removal. Insect visitation rates were calculated for each plant as the number of flowers visited per minute corrected by the total flower number of this species present in the plot (hereafter visitation rate). Visual identification of insects during the censuses was feasible, thus their capture for further taxonomic identification was only done at the end of the experiment to reduce the impact in visitation rates.

To account for differences in the visitation rates in the presence and after removal of $O$. pes-caprae, for each plant species, generalized estimating equation (GEE) was fit to the data with ProcGenmod models (SAS 9.2 1999), with "Presence of O. pes-caprae" as fixed factor and with a gamma logit function. This type of analysis was chosen because normality was not achieved in the data distribution.

\section{Plant-pollinator network}

Using the data gathered, a plant-pollinator interaction network was constructed for the studied community in the presence and after removal of $O$. pes-caprae. Networks were represented as two-dimensional matrices, with rows representing the plants and columns
Table 1 Native species studied in the locality of Castelo Viegas (Coimbra, Portugal): flowering period in the Iberian Peninsula [from COI voucher records and confirmed in
Castroviejo et al. (1986-2012)], estimated total abundance of flowers (abundance), breeding system, number of ovules per flower (No. ovules/flower) and references

\begin{tabular}{|c|c|c|c|c|c|c|}
\hline Species & Family & Phenology & $\begin{array}{l}\text { Abundance } \\
\text { (total } \\
\text { number } \\
\text { of flowers) }\end{array}$ & Breeding system & $\begin{array}{l}\text { No. ovules/ } \\
\text { flower }\end{array}$ & References \\
\hline $\begin{array}{l}\text { Fumaria } \\
\text { muralis }\end{array}$ & Fumariaceae & $\mathrm{I}-\mathrm{X}$ & 7,350 & Self-compatible & $\begin{array}{l}2 \text { (1 always } \\
\text { aborts) }\end{array}$ & Soler (1983) \\
\hline $\begin{array}{l}\text { Raphanus } \\
\text { raphanistrum }\end{array}$ & Brassicaceae & $\mathrm{I}-\mathrm{XII}$ & 800 & Self-incompatible & Up to 8 & $\begin{array}{l}\text { Sampson (1964), } \\
\text { Conner et al. (1996) }\end{array}$ \\
\hline Vicia faba & Fabaceae & II-IX(XII) & 920 & Self-compatible & Up to 9 & Romero Zarco (1999) \\
\hline $\begin{array}{l}\text { Brassica } \\
\quad \text { oleracea }\end{array}$ & Brassicaceae & III-VIII & 1,840 & Self-incompatible & Up to 23 & $\begin{array}{c}\text { Nasrallah et al. (1988), } \\
\text { Gurusamy (1999) }\end{array}$ \\
\hline $\begin{array}{c}\text { Melilotus } \\
\text { italicus }\end{array}$ & Fabaceae & III-VI & 6,100 & Self-compatible* & $\begin{array}{l}8 \text { (only } 1-2 \text { seeds } \\
\text { develop) }\end{array}$ & $\begin{array}{l}\text { Gettys and Johnson } \\
\text { (1944) }\end{array}$ \\
\hline V. sativa & Fabaceae & III-VI & 25 & Self-compatible & Up to 13 & Galloni et al. (2007) \\
\hline
\end{tabular}

* Considering M. officinalis is self-pollinated (Akhalkatsi et al. 1999) 
representing the pollinator species. The cell values expressed the frequency of visits observed for each plant-pollinator interaction. The cumulative networks were visualized using a code written in Mathematica 6.0 (Wolfram Research 2007), which allows incorporating the total abundance of each plant species in the community. Afterwards, indices of the network properties were estimated for each matrix: plant $\left(\mathrm{P}_{1}\right)$ and pollinator $\left(\mathrm{P}_{\mathrm{o}}\right)$ species richness, the number of interactions (I) to the plants and the network size $\left(\mathrm{M}=\mathrm{P}_{1} \times \mathrm{P}_{\mathrm{o}}\right)$. Connectance, that is, the proportion of possible links between species that are realized, $\mathrm{C}=100 \times(\mathrm{I} / \mathrm{M})$ and plant linkage level $\left(\mathrm{I} / \mathrm{P}_{1}\right)$, that is, the number of links of a species to other species, were calculated. Connectivity among native species may decline in highly invaded networks, since some invasive species usurp interaction links either by participating in most asymmetric interactions or by playing a role as central nodes in the invaded network structure (Aizen et al. 2008). For this reason, we expected the connectance and the plant linkage level $\left(\mathrm{I} / \mathrm{P}_{1}\right)$ to increase after $O$. pes-caprae removal. The $\mathrm{R}$ package bipartite 1.12 (Dormann et al. 2009) was used to calculate whether the robustness was greater after $O$. pes-caprae removal, since a trend towards increased stability in restored plots was expected (Forup et al. 2008). Robustness was calculated as the area below the extinction curve following Memmott et al. (2004). The curve is based on the fact that if a given fraction of the pollinators is eliminated, a number of plant species, which depend on their interactions, become extinct. Finally, we used the program ANINHADO to calculate the nestedness (Guimaraes and Guimaraes 2006; Almeida-Neto et al. 2008). Networks are considered nested when the species interacting with specialists are a proper subset of the species interacting with generalists. Super-generalist invaders may increase the overall value of nestedness of the network if they become central nodes (i.e. most connected species) in the nested matrix (Bjerknes et al. 2007; Bartomeus et al. 2008b; Tylianakis et al. 2010). Since only two values were obtained for these network properties, no statistical comparisons were made for all these indices.

In addition to these indices, the $\mathrm{R}$ package bipartite 1.12 (Dormann et al. 2009) was used to estimate other parameters describing network topology at the individual species level (using the function species level) in the presence and after removal of $O$. pes-caprae. Because many invasive plants are highly generalists, their interactions with other species could become central in the structure of modified plant-pollinator networks (Aizen et al. 2008); thus, values of parameters describing network topology are expected to change in the presence and after removal of $O$. pes-caprae. The studied parameters (at both pollinator and plant levels) were the following: (1) Species degree: sum of interactions; (2) Strength: sum of dependencies. Dependence of a plant species on a pollinator is the fraction of visits by that particular pollinator from the total number of visits to the plant; dependence of a pollinator on a plant species is the fraction of the total number of visits made by that pollinator species to that particular plant species (Bascompte et al. 2006); (3) Interaction push/pull: direction of interaction asymmetry; positive value for a plant species indicates that it "affects" pollinators more strongly than pollinators affect it, while negative values indicate that pollinators affect the plant more strongly than the plant affects insects (Vázquez et al. 2007); (4) Paired differences index (PDI): proportion of interactions a species engages in (Poisot et al. 2011a, b); value of 0 indicates generalists, while 1 indicates a perfect specialist; (5) Pollination service index (PSI): expresses the value of a pollinator for all plant species as the sum (across all plant species) of the proportion of pollen deposited per visit; the more specialized the pollinator is and the fewer pollinators the plants it pollinates have, the higher is its value for the plant community; (6) d: specialization of each species based on its discrimination from random selection of partners (see Blüthgen et al. 2006 for details).

To account for differences in the values of these indexes in the presence and after removal of $O$. pescaprae (e.g. comparing the strength at the plant level involved the comparison of all strength values for each plant species with and without $O$. pes-caprae), ANOVAs were carried using SPSS software (version 19, SPSS, Chicago, USA) at the pollinator level. At the plant level, and due to the low number of plants, a Monte Carlo permutation test based on 9999 random replicates was carried with PAST (Hammer et al. 2001). This test was also used for the $d$ index at the pollinator level due to the lack of normality.

Natural pollen loads and pollen tubes

Open flowers of the native species were collected in the presence and after removal of $O$. pes-caprae. For this, some flowers were first selected and their styles were collected previously to $O$. pes-caprae removal. The day 
before weeding, some other flower buds ready to open the next day were marked with labels for their styles to be collected in the same way after $O$. pes-caprae was removed. By this way, it was assured that the later flowers only opened after the removal of O. pes-caprae. In order to avoid bias due to architectural effects, in all cases, we tried to mark flowers located in similar positions within each inflorescence. A minimum of 25 flowers per species was collected in the presence and after $O$. pes-caprae removal. Stigmas and styles were cleared and softened with $8 \mathrm{~N}$ sodium hydroxide for 1-6 $\mathrm{h}$ depending on the species, washed in distilled water and placed overnight in $0.05 \%$ (w/v) aniline blue prepared in $0.1 \mathrm{~N}$ potassium phosphate (Dafni et al. 2005). Afterwards, they were placed in a microscope slide with a drop of glycerine $50 \%$, squashed beneath a coverslip and observed using a Nikon Eclipse 80i epifluorescence microscope (Nikon Instruments, Kanagawa, Japan) equipped with the UV-2A filter cube. The number of conspecific and heterospecific pollen grains in stigmas and pollen tube growth in the upper part of the style was counted for all native plants. For each plant species, an ANOVA was carried to assess differences in these two variables in the presence and after removal of $O$. pes-caprae. Data were log and square-root transformed to achieve normality and homoscedasticity.

Fruit set

As described above for the styles, and at the same time, labels with different colours were used to mark flowers of similar position in the inflorescences that were open in the presence and after removal of $O$. pes-caprae. The labelled flowers were collected 2-3 weeks after to guarantee fruit maturation, and fruit set was calculated as the percentage of flowers developing into fruits considering if pollination occurred in the presence or after $O$. pes-caprae removal. An independent analysis was carried for each species, exploring by a GEE model and an AR(1) correlation matrix in SPSS (version 19, SPSS, Chicago, USA).

\section{Results}

Visitation rates

A total of 1,211 and 1,278 visits were recorded in the presence and after removal of $O$. pes-caprae, respectively. Four plant species showed differences in the visitation rates after $O$. pes-caprae removal (Table 2). Vicia sativa was the species having the highest visitation rates $\left(2.4 \times 10^{-4}\right.$ with and $1.9 \times 10^{-4}$ without $O$. pes-caprae; Fig. 1 a and Tables $\mathrm{S} 1$ and $\mathrm{S} 2$ in Supporting Information). For $F$. muralis, $R$. raphanistrum and $V$. sativa, visitation rates were significantly higher in the presence of $O$. pes-caprae than after its removal; the opposite was observed for $B$. oleracea. No significant differences due to the removal of $O$. pes-caprae were found for $V$. faba and M. italicus (Table 2; Fig. 1a).

The plant-pollinator network

The two pollination networks comprised 13 visitor species and 6 native plant species, plus $O$. pes-caprae before removal in one of them. Network size with $O$. pes-caprae was 91 , with the plant species displaying 49 different links (Fig. 2a; Table 3). Network size after removal of $O$. pes-caprae was 78, with 38 links (Fig. 2b; Table 3).

Index values in the presence of $O$. pes-caprae and after its removal are summarized in Table 3. The two networks were significantly nested $(P=0.0$ and $P=0.1$ in the presence of $O$. pes-caprae and after its removal, respectively). In relation to the analysis at the species level (i.e. for each of the species; $N=6$ for plants and $\mathrm{N}=13$ for pollinators), there were no significant differences in any of the indexes considered in the presence and after removal of $O$. pescaprae (Table 3). Comparisons of $d$ values at the plant level were not feasible due to homogeneity in variance.

Natural pollen loads and pollen tubes

The number of conspecific pollen grains on the stigmas was significantly different in two native species only, with conspecific pollen loads being higher for $V$. sativa and lower for M. italicus in the presence of $O$. pes-caprae (Table 2; Fig. 1b). The heterospecific pollen grains did not differ in any of the species in the presence and after removal of the invasive plant (Table 2). The number of pollen grains of $O$. pes-caprae on the stigmas of native plants was negligible after its removal.

With respect to the pollen tubes development, our results showed statistically significant differences for 
Table 2 Differences in visitation rates, conspecific and heterospecific pollen loads, pollen tubes and fruit set of the native plants studied in the presence and after $O$. pes-caprae removal

\begin{tabular}{|c|c|c|c|c|c|c|c|c|c|c|c|c|c|c|c|}
\hline & \multicolumn{3}{|c|}{ Visitation rates } & \multicolumn{3}{|c|}{ Conspecific pollen loads } & \multicolumn{3}{|c|}{$\begin{array}{l}\text { Heterospecific pollen } \\
\text { loads }\end{array}$} & \multicolumn{3}{|c|}{ Pollen tubes } & \multicolumn{3}{|c|}{ Fruit set } \\
\hline & $d f$ & $\chi^{2}$ & $P$ & $d f$ & $F$ & $P$ & $d f$ & $F$ & $P$ & $d f$ & $F$ & $P$ & $d f$ & Wald $\chi^{2}$ & $P$ \\
\hline F. muralis & 1 & 6.140 & $0.0132^{+}$ & 1,58 & 0.068 & 0.795 & 1,58 & 2.496 & 0.120 & 1,58 & 0.240 & 0.626 & 1 & 2.266 & 0.132 \\
\hline R. raphanistrum & 1 & 54.64 & $<0.001^{+}$ & 1,54 & 1.130 & 0.293 & 1,54 & 3.225 & 0.78 & 1,54 & 9.680 & $\mathrm{0.003}^{+}$ & 1 & 1.280 & 0.258 \\
\hline V. $f a b a$ & 1 & 0.005 & 0.9453 & 1,58 & 2.428 & 0.125 & 1,58 & 0.322 & 0.573 & 1,58 & 1.817 & 0.183 & 1 & 4.840 & $0.028^{+}$ \\
\hline B. oleracea & 1 & 10.80 & $0.001^{-}$ & 1,58 & 0.014 & 0.905 & 1,58 & 0.787 & 0.379 & 1,58 & 29.180 & $<0.001^{-}$ & 1 & 1.726 & 0.189 \\
\hline M. italicus & 1 & 0.03 & 0.872 & $\mathbf{1}, 58$ & 19.471 & $<0.001^{-}$ & 1,58 & 0.305 & 0.583 & $\mathbf{1}, 58$ & 25.963 & $<0.001^{-}$ & 1 & 6.304 & $\mathrm{o.012}^{+}$ \\
\hline$V$. sativa & 1 & 10.35 & $\mathbf{0 . 0 0 1 3}^{+}$ & 1,58 & 5.208 & $0.026^{+}$ & 1,58 & 0.778 & 0.381 & 1,58 & 2.088 & 0.154 & 1 & 0.003 & 0.953 \\
\hline
\end{tabular}

Values differ significantly at $P<0.05 .{ }^{+}$means higher and ${ }^{-}$means lower values in the presence of $O$. pes-caprae. The tests where significant differences were obtained are highlighted in bold

R. raphanistrum, B. oleracea and $M$. italicus, with the number of pollen tubes being higher in B. oleracea and $M$. italicus and lower in $R$. raphanistrum in the presence of $O$. pes-caprae than after its removal (Table 2; Fig. 1c).

Fruit set

A significantly higher fruit production was found in the presence of $O$. pes-caprae for $V$. faba and M. italicus (Table 2; Fig. 1d). For the remaining plant species, no significant differences in fruit set in the presence and after removal of $O$. pes-caprae were found (Table 2; Fig. 1d), despite that in all cases, a trend towards an increase in fruit set was observed in the presence of the invasive plant.

\section{Discussion}

Management measures related to the removal of invasive plants should consider the possible negative impacts on co-flowering plants through changes in pollinator populations (Carvalheiro et al. 2008). Still, the effects of invasive species on the reproductive success of native species have been proposed to vary among species, being dependent on their breeding system, pollination specialization and/or life history traits (Totland et al. 2006).

In this study, the removal of $O$. pes-caprae seems to have little effects on the composition of the pollinator community. Oxalis pes-caprae was frequently visited by generalist insects like bees, specifically Apis mellifera, Anthophora sp. and Bombus sp. (results herein and in Costa 2012). Our results show that $O$. pes-caprae was facilitating pollination (i.e. increasing visitation rates) of $F$. muralis, $R$. raphanistrum and $V$. sativa. However, the higher visitation rates in the presence of $O$. pes-caprae were not reflected later in significant differences in the fruit set of these native species, although there was a clear tendency to a higher production of fruits in all of them. Strong impacts on the visitation rates to the native species without effects on native's seed production have already been reported for some invasive species [e.g. Phacelia tanacetifolia in Totland et al. (2006)]. Different scenarios, not mutually exclusive, can be proposed to explain such absence of effect on the final reproductive output. First, O. pes-caprae might attract to the study site a higher number of pollinators (e.g. Anthophora sp. and Apis mellifera) that are not as efficient as the ones observed in the community after its removal (e.g. Andrena sp.). Thus, in the presence of $O$. pes-caprae, a relative lower number of more efficient pollinators are present than it its absence, resulting in a similar fruit set. However, no differences were observed in several network parameters associated with specialization, such as Pollinator service index (PSI) and Paired differences index (PDI). The apparent contradiction between these shifts in pollinators' efficiency and the absence of differences in several network parameters associated with specialization, assuming that greater specialization implies greater efficiency, may have resulted from the absence of an overall trend in all species, which could be weakening the dissimilarities in the index values. In fact, when looking to these indices in particular for $F$. muralis, $R$. raphanistrum and $V$. sativa, their values 

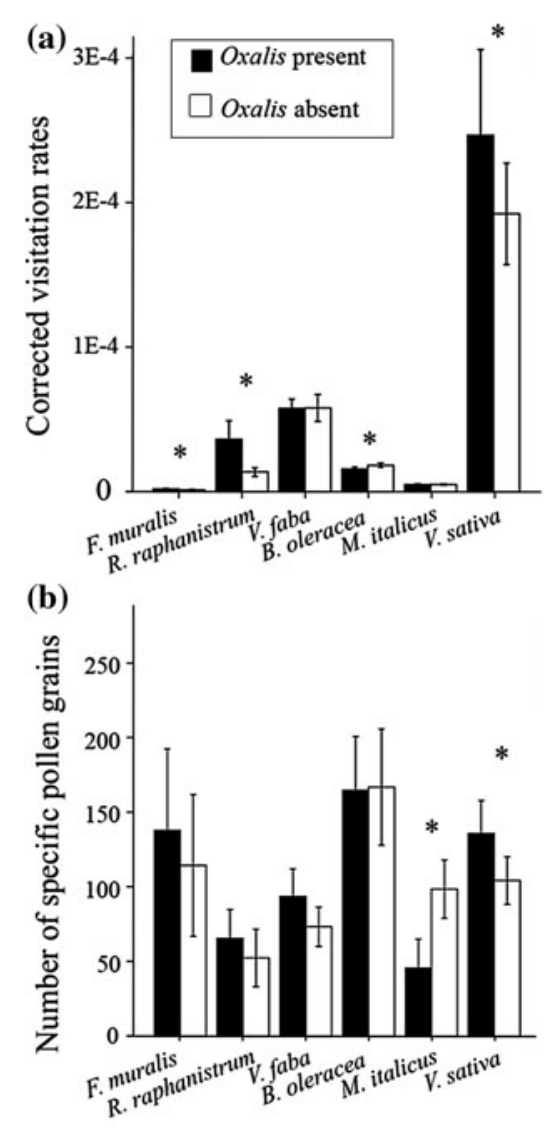

(c)
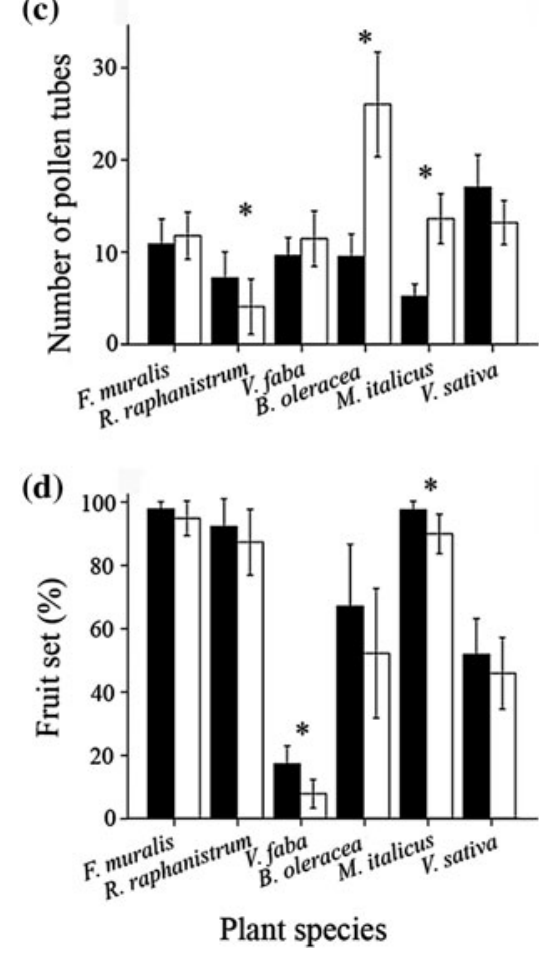

4Fig. 1 Corrected visitation rate (a), natural pollen loads (b), pollen tubes (c) and fruit set (percentage of flowers developing into fruits) (d) in native species in the presence (black bars) and after removal of Oxalis pes-caprae (white bars). Bars indicate mean $\pm 2 \times$ standard error. *Indicate significant differences at $P<0.05$

are greater when $O$. pes-caprae is removed, meaning that pollinators are more specialized in the absence of this invasive plant (data not shown).

Secondly, besides differences in efficiency, pollinators might have different behaviours (constancy and preferences), which could also be influenced by invasive species. When invaders become dominant in the community, an additional and new food resource is offered, which might change the behaviour of the pollinators in the community. Indeed, invasive species frequently drive changes in the foraging behaviour of pollinators rather than in their abundance (Ghazou 2004). These changes alter constancy and preference indices to the native plants, potentially affecting their fitness, by decreasing the quality and quantity of the pollen delivered or by increasing heterospecific pollen deposition (Harder and Routley 2006; Flanagan et al. 2009). Increased heterospecific pollen deposition might detrimentally affect the fitness of the plants regardless of the increased visitation rates and might explain the lack of differences in native plant fitness. However, our results do not corroborate this hypothesis since no differences were obtained in heterospecific pollen deposition. Alternatively, differences in the quality of the pollen might have occurred, because, despite not significant, pollen tube development was overall lower in the presence of $O$. pescaprae than after its removal, regardless of the higher pollen loads (and visitation rates) observed in the former. Additionally, allelopathic effects of heterospecific on conspecific pollen grains and lock of the stigmatic lobes may limit conspecific pollen germination and pollen tube growth (Feinsinger 1987), ultimately affecting fruit set. If this is the case, the heterospecific pollen loads would explain the lack of differences in $V$. sativa and $R$. raphanistrum fruit sets in the presence and after removal of $O$. pes-caprae, regardless of the conspecific pollen loads and pollen tubes growth along the style.

Thirdly, it has been hypothesized that native species that are more susceptible to pollen limitation are expected to bear greater fitness disadvantages in 


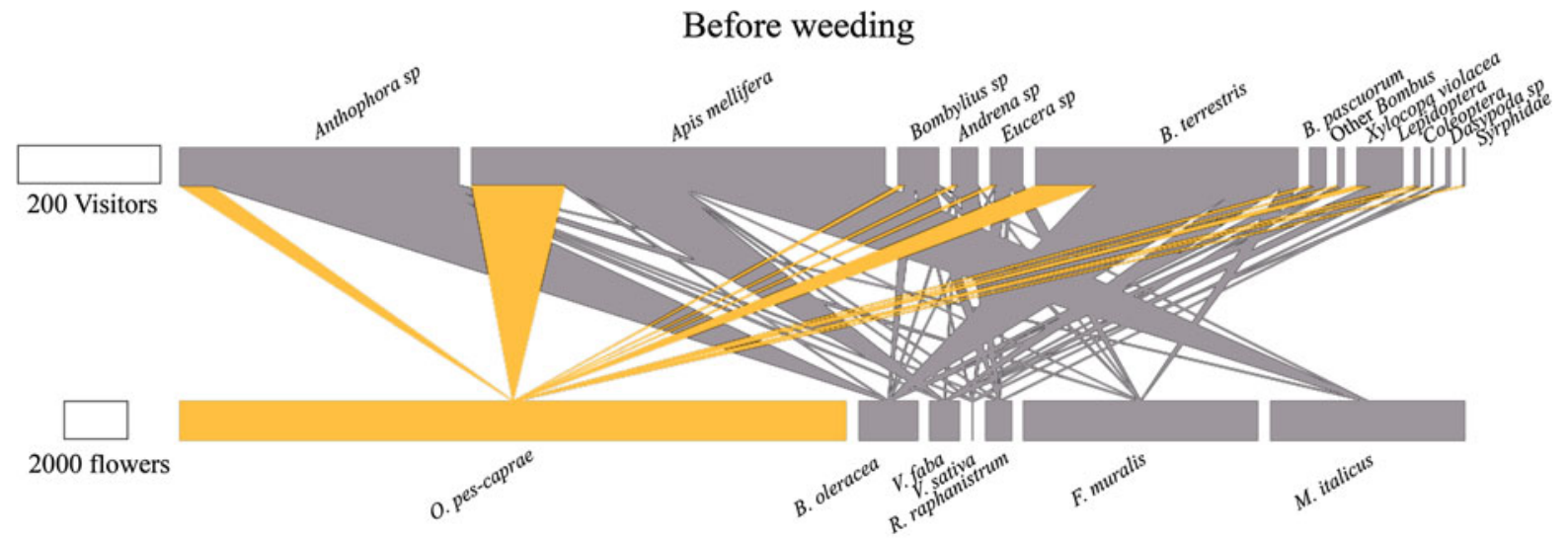

After weeding

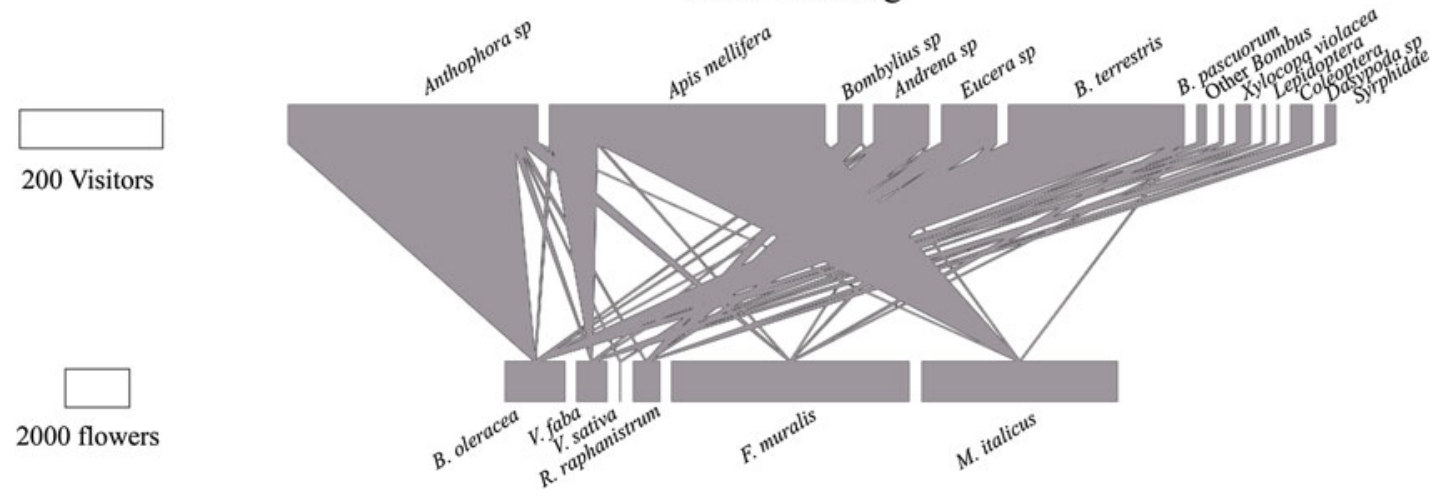

Fig. 2 Flower visitation network for the plant community studied in the presence and after removal of Oxalis pes-caprae. The width of the rectangles represents the total species abundance, and the size of the lines connecting them represents

habitats with high invasive plant abundances (Dietzsch et al. 2011). Two of the native plants, where no effect on reproductive success was observed (F. muralis and $R$. raphanistrum), present low number of ovules (up to 8). In light of the results for fruit set, it seems that these plants are not pollinator-limited ( $>90 \%$ fruit set, both with and without $O$. pes-caprae) and, thus, they are able to reach optimal reproductive success even if the number of visitations decreases.

A similar fruit set was also found in B. oleracea in the presence and after removal of $O$. pes-caprae. Still, in this case, the presence of $O$. pes-caprae appears to have a slightly negative effect on the visitation rate. Considering that $B$. oleracea is a self-incompatible species and that there is a decrease in the number of pollen tubes in the presence of $O$. pes-caprae, despite no differences in the pollen loads were detected, it seems that $O$. pes-caprae increases selfing rates in this the frequency of interaction in the studied community. The interactions with $O$. pes-caprae are shown in yellow. Scale bars for the number of flowers and insects are also provided. (Color figure online)

species. Anyway, these negative effects on visitation rates and pollen tubes did not appear to be high enough to significantly influence its reproductive success (70 and $50 \%$ in the presence and after removal of $O$. pescaprae, respectively).

A different scenario occurred in $V$. faba and $M$. italicus, where no differences in visitation rates were found. In those species, the presence of $O$. pescaprae significantly increased their fruit production, similar to what has been described for the native Diplotaxis erucoides (Jakobsson et al. 2009). This could be attributed to pollen quality, which is known to affect seed and fruit production in several ways. Reproductive success may depend on the degree of kinship of conspecific pollen to the pistil on which it arrives, intrinsic genetic quality of specific pollen donors, diversity of pollen donors or the effects of foreign pollen during the transport and germination of 
Table 3 Results for the network overall properties characterization and for the ANOVA (for the Pollinator level) and Monte Carlo permutation test based on 9999 random replicates (for the plant level) carried for indices at the species level in the presence and after Oxalis pes-caprae removal

\begin{tabular}{|c|c|c|c|}
\hline & \multicolumn{2}{|c|}{ In presence } & $\begin{array}{l}\text { After } \\
\text { removal }\end{array}$ \\
\hline \multicolumn{4}{|l|}{ Index } \\
\hline Network size & \multicolumn{2}{|l|}{91} & 78 \\
\hline Number of links & \multicolumn{2}{|l|}{49} & 38 \\
\hline Connectance & \multicolumn{2}{|c|}{$\begin{array}{l}53.84(51.39 \text { only } \\
\text { natives) }\end{array}$} & 48.71 \\
\hline Plant linkage level & \multicolumn{2}{|l|}{7} & 6.33 \\
\hline Robustness & \multicolumn{2}{|l|}{0.67} & 0.70 \\
\hline $\begin{array}{l}\text { Nestedness } \\
{[\text { NODF(Er)] }}\end{array}$ & \multicolumn{2}{|l|}{53.07} & 48.71 \\
\hline & & $F$ & $P$ \\
\hline \multicolumn{4}{|l|}{ Index at species level } \\
\hline \multicolumn{4}{|l|}{ Pollinator level } \\
\hline \multicolumn{2}{|l|}{ Species degree } & 1.613 & 0.216 \\
\hline \multicolumn{2}{|l|}{ Normalized degree } & 0.259 & 0.615 \\
\hline \multicolumn{2}{|l|}{ Strength } & 0.261 & 0.614 \\
\hline \multicolumn{2}{|l|}{ Interaction push/pull } & 0.206 & 0.654 \\
\hline \multicolumn{2}{|c|}{ Paired differences index (PDI) } & 0.110 & 0.743 \\
\hline \multicolumn{2}{|c|}{ Pollination service index (PSI) } & 0.602 & 0.445 \\
\hline \multicolumn{2}{|l|}{$d^{*}$} & -0.234 & 0.817 \\
\hline & & $t$ & $P$ \\
\hline
\end{tabular}

Plant level

$\begin{array}{lcl}\text { Species degree } & -0.105 & 0.919 \\ \text { Normalized degree } & -0.105 & 0.919 \\ \text { Strength } & -0.275 & 0.789 \\ \text { Interaction push/pull } & -0.344 & 0.738 \\ \text { Paired differences index (PDI) } & -0.193 & 0.851 \\ \text { Pollination service index (PSI) } & -0.542 & 0.599 \\ \text { d } & - & -\end{array}$

For description of each index see the "Materials and methods" section. Significance level at $P<0.05$

*Monte Carlo permutation test

conspecific pollen (Brown et al. 2002; Mitchell et al. 2009). The observed results for these two species could be explained if the presence of $O$. pes-caprae affected the behaviour of the pollinators by favouring intra-conspecific plant movements among genetically superior pollen donors, thus increasing pollen quality and consequently pollinator efficiency. Additional support for this idea can be found in M. italicus, in which the presence of $O$. pes-caprae seemed to negatively influence the number of conspecific pollen grains and pollen tubes developed along the style, but with no effect on seed production. Also, dissimilarities in fruit set could result from variations in the phenology, in case the reproductive investment varies during the flowering season. However, considering the long flowering phenology of the studied species and the temporal extent of the experiment (2 weeks), such hypothesis is not so probable.

Regarding the network analysis, integration of one invasive species into a plant-pollinator network has been found to have no effect on the overall network connectance, although connectance among native species may decline (Aizen et al. 2008). Connectance values were similar in the presence and after removal of $O$. pes-caprae. These values were low as commonly observed in mutualistic networks (e.g. Jordano 1987; Olesen and Jordano 2002) and corroborate the findings that the influence of a single invasive species in the network, even if it establishes a great number of interactions, can be buffered by the rearrangement of native plant-pollination interactions after invasion (Vilà et al. 2009). In respect of the Plant linkage level, it is expected to increase if the invasive plant fosters facilitation over competition for pollinators, that is, if it promotes new interactions between pollinators and native plants (Padrón et al. 2009). In fact, facilitation was found in three species (F. muralis, $R$. raphanistrum and $V$. sativa, see above), and the values of Plant linkage level seem to be greater in the presence of O. pes-caprae (although not statistically analysed). Robustness values also appeared to be similar both in the presence and after the removal of the invader. The relative tolerance of plant-pollinator networks to extinction after species removal has already been argued to derive from redundancy in pollinators per plant and from nested topology of the networks (Memmott et al. 2004, but see Kaiser-Bunbury et al. 2010). Generalist invasive plants can play an important role in the networks, but in this case, it seems that the structure of the network is robust to the removal of O. pes-caprae. The fact that many plant-pollinator interactions are generalized (Jordano 1987; Waser et al. 1996) may facilitate the integration of invasive plants into the network (Memmott and Waser 2002; Lopezaraiza-Mikel et al. 2007) and, at the same time, make the native networks more robust and resilient to 
changes in species composition (Memmott et al. 2004).

On the other hand, generalist invasive plant species are expected to compete for pollination with natives when they monopolize many pollinator species or when they attract pollinators of a highly specialist plant. If generalist invasive plant establishes many interactions with resident pollinators, some interactions with native plant species will be lost and this would increase network nestedness, as a greater number of pollinator species interact with lower number of plants (Bartomeus et al. 2008b). In our system, nested values in the presence and after removal of $O$. pes-caprae were larger than previously described for some other invaded systems (e.g. in Vilà et al. 2009), but the degree of nestedness seemed to be greater in the presence of $O$. pes-caprae (not statistically analysed).

In our system, in which a high number of plantpollinator interactions were found, the presence of a super-generalist invasive species does not appear to have any effect on the structure and topology of the network. It is also important to note the possible density-dependent effects between visitation rates and floral density, since interactions between invasive and native plants for pollination can be subjected to relative invasive plants abundance in a similar way as usual interactions among native plant species (Rathcke 1983; Muñoz and Cavieres 2008; Dietzsch et al. 2011). O. pes-caprae was extremely abundant in the studied community when compared to the remaining species, being expectable to have a high impact in terms of community changes. Interestingly, at pollinator's level this was not the case, as even at these high densities, $O$. pes-caprae appeared not to be a strong competitor for pollinators, being rather a facilitative species. This overwhelming unexpected outcome implies, in addition, that the removal of more than $90 \%$ of the flowers in this area had no evident effects on the pollination of the remaining native plant species, supporting previous simulations on species removal (e.g. Memmott et al. 2004) where a high network tolerance to extinctions was found (but see Valdovinos et al. 2009).

Still, in ecological studies, the spatial and temporal scales are often small and short (e.g. Guitián et al. 1996; Roubik 2001; Price et al. 2005), limiting generalizations of the results obtained at a local patch scale. In fact, little is known about how changes in temporal and spatial scales affect the species and functional composition of pollinator communities (see review in Bjerknes et al. 2007). O. pes-caprae blooms early in the year, having a low number of co-flowering species, and the available resources are scarce. Under this scenario and considering the dense stands formed by $O$. pes-caprae in the landscape, it could be hypothesized that this species currently functions as a major food resource for insects at that specific time of the year. In this case, the temporal scale of the current study could be too small and short to observe differences in the pollination services. Further studies considering a larger geographical scale through the complete season would be needed to confirm these hypotheses. Anyway, the removal of $O$. pes-caprae appears to have no effect on the pollinator's array in the studied community and have variable effects on the visitation rates to co-flowering native species and so in their reproductive success. Still, our results highlight the importance of evaluating both the quantitative and qualitative impacts of invasive species on the reproductive success of co-flowering native plants.

Acknowledgments The authors thank D. Rojas for helping in network analysis, J. Memmott for kindly sharing network drawing codes, and A. Vale and R. Heleno for their helpful discussion of the manuscript. We also thank the COI herbarium (University of Coimbra) for allowing voucher specimens examination and Prof. J. Delgado Domingos and R. Trancoso (METEO-IST group, University of Lisbon, Portugal) for climate data supply. This work is financed by FEDER funds through the COMPETE Program and by Portuguese Foundation for Science and Technology (FCT) funds in the ambit of the project PTDC/ BIA-BIC/110824/2009, by CRUP Acções Integradas LusoEspanholas 2010 with the project E10/10, by MCI-Programa de Internacionalización de la I + D (PT2009-0068) and by the Spanish DGICYT (CGL2009-10466), FEDER funds from the European Union, and the Xunta de Galicia (INCITE093103009PR). FCT also supported the work of S. Castro (FCT/ BPD/41200/2007) and J. Costa (CB/C05/2009/209; PTDC/ BIA-BIC/110824/2009). The work of V. Ferrero was supported by the Fundación Ramón Areces.

\section{References}

Aizen M, Morales C, Morales J (2008) Invasive mutualists erode native pollination webs. PLoS Biol 6(2):e31

Akhalkatsi M, Pfauth M, Calvin CL (1999) Structural aspects of ovule and seed development and nonrandom abortion in Melilotus officinalis (Fabaceae). Protoplasma 108:211-223

Almeida-Neto M, Guimaraes P, Guimaraes PR, Loyola RD, Ulrich W (2008) A consistent metric for nestedness 
analysis in ecological systems: reconciling concept and measurement. Oikos 117:1227-1239

Bartomeus I, Bosch J, Vilà M (2008a) High invasive pollen transfer, yet low deposition on native stigmas in a Carpobrotus-invaded community. Ann Bot 10:417-424

Bartomeus I, Vilà M, Santamaría L (2008b) Contrasting effects of invasive plants in plant-pollinator networks. Oecologia 155:761-770

Bascompte J, Jordano P, Olesen JM (2006) Asymmetric coevolutionary networks facilitate biodiversity maintenance. Science 312:431-433

Bjerknes AL, Totland O, Hegland SJ, Nielsen ACN (2007) Do alien plant invasions really affect pollination success in native plant species? Biol Conserv 138:1-12

Blüthgen N, Menzel F, Blüthgen N (2006) Measuring specialization in species interaction networks. BMC Ecol 6:9

Brandes D (1991) Sociology and ecology of Oxalis pes-caprae L. in the Mediterranean region with special attention to Malta. Phytocoenologia 19:285-306

Brown BJ, Mitchell RJ, Graham SA (2002) Competition for pollination between an invasive species (purple loosestrife) and a native congener. Ecology 83:2328-2336

Carvalheiro LG, Barbosa ERM, Memmott J (2008) Pollinator networks, alien species and the conservation of rare plants: Trinia glauca as a case study. J Appl Ecol 45:1419-1427

Castro S, Loureiro J, Santos C, Ater M, Ayensa G, Navarro L (2007) Distribution of flower morphs, ploidy level and sexual reproduction of invasive weed Oxalis pes-caprae in the western area of the Mediterranean Region. Ann Bot 99:507-517

Castro S, Ferrero V, Costa J, João Sousa A, Castro M, Navarro L, Loureiro J (2013) Reproductive strategy of the invasive Oxalis pes-caprae: distribution patterns of floral morphs, ploidy levels and sexual reproduction. Biol Invasions. doi: 10.1007/s10530-013-0414-2

Chittka L, Schürkens S (2001) Successful invasion of a floral market. Nature 411:653

Conner JK, Rush S, Jennetten P (1996) Measurements of natural selection on floral traits in wild radish (Raphanus raphanistrum) I Selection through lifetime female fitness. Evolution 50:1127-1136

Costa J (2012) Sexual reproduction of the pentaploid shortstyled Oxalis pes-caprae. Msc thesis, Centre for Functional Ecology, Department of Life Sciences, FCTUC

Costa J, Ferrero V, Loureiro J, Castro M, Navarro L, Castro S (2013) Sexual reproduction of the pentaploid, short-styled Oxalis pes-caprae allows the production of viable offspring. Plant Biol. doi:10.1111/plb.12010

Dafni A, Pacini E, Nepi M (2005) Pollen and stigma biology. In: Dafni A, Kevan P, Husband B (eds) Practical pollination biology. Enviroquest, Ontario, pp 83-142

Damanakis M, Markaki M (1990) Studies on the biology of Oxalis pes-caprae L. under field conditions in Crete Greece. Zizaniology 2:145-154

Dietzsch AC, Stanley DA, Stout JC (2011) Relative abundance of an invasive alien plant affects native pollination processes. Oecologia 167:469-479

Dormann CF, Fründ J, Blüthgen N, Gruber B (2009) Indices, graphs and null models: analyzing bipartite ecological networks. Open Ecol J 2:7-24
Feinsinger P (1987) Effects of plant species on each other's pollination: is community structure influenced? Trends Ecol Evol 2:123-126

Flanagan RJ, Mitchell RJ, Knutowski D, Karron JD (2009) Interspecific pollinator movements reduce pollen deposition and seed production in Mimulus ringens (Phrymaceae). Am J Bot 96:809-815

Forup ML, Henson KSE, Craze PG, Memmott J (2008) The restoration of ecological interactions: plant-pollinator networks on ancient and restored heathlands. J Appl Ecol 45:742-752

Galil J (1968) Vegetative dispersal in Oxalis cernua. Am J Bot 55:68-73

Galloni M, Podda L, Vivarelli D, Cristofolini G (2007) Pollen presentation, pollen-ovule ratios, and other reproductive traits in Mediterranean Legumes (Fam Fabaceae: Subfam Faboideae). Plant Syst Evol 266:147-164

Castroviejo S (coord gen) (1986-2012) Flora ibérica 1-8, 10-15, 17-18, 21. Real Jardín Botánico, CSIC, Madrid

Gettys RE, Johnson IJ (1944) The nature and inheritance of sterility in sweet clover, Melilotus officinalis Lam. J Am Soc Agron 36:28-37

Ghazou J (2004) Alien abduction: disruption of native plantpollinator interactions by invasive species. Biotropica 36:156-164

Gimeno I, Vilà M, Hulme PE (2006) Are islands more susceptible to plant invasion than continents? A test using Oxalis pes-caprae L. in the western Mediterranean. J Biogeogr 33:1559-1565

Grabas GP, Laverty TM (1999) The effect of purple loosestrife (Lythrum salicaria L.; Lythraceae) on the pollination and reproductive success of sympatric co-flowering wetland plants. Ecoscience 6:230-242

Guimaraes PR, Guimaraes P (2006) Improving the analyses of nestedness for large sets of matrices. Environ Modell Softw 21:1512-1513

Guitián J, Guitián P, Navarro L (1996) Spatio-temporal variation in pollination assemblage of Cornus sanguinea. Acta Oecol 17:285-295

Gurusamy C (1999) The pattern of seed formation in cauliflower (Brassica oleracea L. var botrytis) with special reference to seed abortion. Can J Bot 77:1189-1192

Hammer $\varnothing$, Harper DAT, Ryan PD (2001) PAST: paleontological statistics software package for education and data analysis. Palaeontol Electron 4:9

Harder LD, Routley MB (2006) Pollen and ovule fates and reproductive performance by flowering plants. In: Harder LD, Barrett SCH (eds) Ecology and evolution of flowers. Oxford University Press, Oxford, pp 61-80

Jakobsson A, Padrón B, Traveset A (2009) Competition for pollinators between invasive and native plants: effects of spatial scale of investigation (note). Ecoscience 16:138-141

Jordano P (1987) Patterns of mutualistic interactions in pollination and seed dispersal: connectance, dependence asymmetries, and coevolution. Am Nat 129:657-677

Kaiser-Bunbury CN, Muff S, Memmott J, Müller CB, Caflisch A (2010) The robustness of pollination networks to the loss of species and interactions: a quantitative approach incorporating pollinator behaviour. Ecol Lett 13:442-452 
King VM, Sargent RD (2012) Presence of an invasive plant species alters pollinator visitation to a native. Biol Invasions 14:1809-1818

Larson DL, Royerb RA, Royerb MR (2006) Insect visitation and pollen deposition in an invaded prairie plant community. Biol Conserv 130:148-159

Levine JM, Vilà M, D'Antonio CM, Dukes JS, Grigulis K, Lavorel S (2003) Mechanisms underlying the impacts of exotic plant invasions. Proc R Soc B 270:775-781

Lopezaraiza-Mikel ME, Hayes RB, Whalley MR, Memmott J (2007) The impact of an alien plant on a native plantpollinator network: an experimental approach. Ecol Lett 10:539-550

McKinney AM, Goodell K (2011) Plant-pollinator interactions between an invasive and native plant vary between sites with different flowering phenology. Pl Ecol 212:10251035

Memmott J, Waser NM (2002) Integration of alien plants into a native flower-pollinator visitation web. Proc R Soc B 269:2395-2399

Memmott J, Waser NM, Price MV (2004) Tolerance of pollination networks to species extinctions. Proc R Soc B 271:2605-2611

Mitchell CE, Agrawal AA, Bever JD et al (2006) Biotic interactions and plant invasions. Ecol Lett 9:726-740

Mitchell RJ, Flanagan RJ, Brown BJ, Waser NM, Karron JD (2009) New frontiers in competition for pollination. Ann Bot 103:1403-1413

Montero-Castaño A, Vilà M (2012) Impact of landscape alteration and invasions on pollinators: a meta-analysis. J Ecol 100:884-893

Moragues E, Traveset A (2005) Effect of Carpobrotus spp on the pollination success of native plant species of the Balearic Islands. Biol Conserv 122:611-619

Morales C, Traveset A (2009) A meta-analysis of impacts of alien vs. native plants on pollinator visitation and reproductive success of co-flowering native plants. Ecol Lett 12:716-728

Muñoz AA, Cavieres LA (2008) The presence of a showy invasive plant disrupts pollinator service and reproductive output in native alpine species only at high densities. J Ecol 96:59-467

Nasrallah JB, Yu S-M, Nasrallah ME (1988) Self-incompatibility genes of Brassica oleracea: expression, isolation, and structure (S locus/transcript localization). Proc R Soc B 85:5551-5555

Olesen J, Jordano P (2002) Geographic patterns in plant-pollinator mutualistic networks. Ecology 83:2416-2424

Padrón B, Traveset A, Biedenweg T, Diaz D, Olesen JM, Nogales M (2009) Impact of invasive species in the pollination networks of two different archipelagos. PLoS One 4:e6275

Poisot T, Lepennetier G, Martinez E, Ramsayer J, Hochberg ME (2011a) Resource availability affects the structure of a natural bacteria-bacteriophage community. Biol Lett 7:201-204

Poisot T, Bever JD, Nemri A, Thrall PH, Hochberg ME (2011b) A conceptual framework for the evolution of ecological specialisation. Ecol Lett 14:841-851
Price MV, Waser NV, Irwin RE, Campbell DR, Brody AK (2005) Temporal and spatial variation in pollination of a montane herb: a seven-year study. Ecology 86:2106-2116

Pütz N (1994) Vegetative spreading of Oxalis pes-caprae (Oxalidaceae). Pl Syst Evol 191:57-67

Rathcke B (1983) Competition and facilitation among plants for pollination. In: Real L (ed) Pollination biology. Academic Press, New York, pp 305-329

Richardson DM, Allsopp N, D'Antonio CM, Milton SJ, Rejmánek M (2000) Plant invasions-the role of mutualisms. Biol Rev 75:65-93

Romero Zarco C (1999) Vicia L. In: Castroviejo S (ed) Flora Iberica: plantas vasculares de la Península Iberica e islas Baleares. Real Jardín Botánico, Madrid, pp 360-417

Roubik DW (2001) Ups and downs in pollinator populations: when is there a decline? Conserv Ecol 5:2

Sampson DR (1964) A one-locus self-incompatibility system in Raphanus raphanistrum. Can J Genet Cytol 6:435-445

SAS Institute (1999) SAS/STAT user's guide, release, 92nd edn. SAS Institute Inc., Cary, NC

Soler A (1983) Revisión de las especies de Fumaria de la Península Ibérica e Islas Baleares. Lagascalia 11:141-228

Totland O, Nielsen A, Bjerknes A-L, Ohlson M (2006) Effects of an exotic plant and habitat disturbance on pollinator visitation and reproduction in a boreal forest herb. Am J Bot 93:868-873

Traveset A, Richardson D (2006) Biological invasions as disruptors of plant reproductive mutualisms. Trends Ecol Evol 21:208-216

Tylianakis JM, Laliberté E, Nielsen E, Bascompte J (2010) Conservation of species interaction networks. Biol Conserv 143:2270-2279

Valdovinos FS, Ramos-Jiliberto R, Flores JD, Espinoza C, López G (2009) Structure dynamics of pollination networks: the role of alien plants. Oikos 118:1190-1200

Vázquez DP, Melián CJ, Williams NM, Blüthgen N, Krasnov BR, Poulin R (2007) Species abundance and asymmetric interaction strength in ecological networks. Oikos 116:1120-1127

Veitch CR, Clout MN (2002) Turning the tide: the eradication of invasive species. Proceedings of the international conference on eradication of island invasives. IUCN Species Survival Commission, Aukland, NZ

Vilà M, Bartomeus I, Dietzsch AC, Petanidou T, SteffanDewenter I, Stout JC, Tscheulin T (2009) Invasive plant integration into native plant-pollinator networks across Europe. Proc R Soc B 276:3887-3893

Vitousek PM (1990) Biological invasions and ecosystem processes: towards an integration of population biology and ecosystem studies. Oikos 57:7-13

Waser NM, Chittka L, Price MV, Williams NM, Ollerton J (1996) Generalization in pollination systems, and why it matters. Ecology 77:1043-1060

Wolfram Research (2007) Mathematica Version 60. Wolfram Research, Champaign, IL

Zavaleta ES, Hobbs RJ, Mooney HA (2001) Viewing invasive species removal in a whole-ecosystem context. Trends Ecol Evol 16:454-459 